\title{
Casos de Ensino na Pós-Graduação: um mergulho em casos reais sobre os jogos de negócios
}

\author{
Post graduation teaching case: diving in real cases about business games
}

\author{
Sidney Pires Martins' ${ }^{1}$, Mateus José dos Santos ${ }^{2}$, Rita Márcia Andrade Vaz de Mello ${ }^{3}$
}

\begin{abstract}
RESUMO: O presente trabalho descreve um caso de ensino elaborado para a disciplina de Jogos de Negócios, ofertada por um curso de pós-graduação Lato Sensu em Gestão Financeira de uma Instituição de Ensino Superior da cidade de Viçosa-MG. Na ocasião, os 21 estudantes matriculados na disciplina foram divididos em quatro grupos e, por meio do WhatsApp, os discentes interagiram entre si com o objetivo de resolver um caso de ensino que apresentava uma situação-problema real. As interações foram mediadas pelas tecnologias e cada grupo recebeu um perfil de cliente diferente que precisaria ser estudado entre os integrantes de cada equipe e, ao final, cada grupo precisaria apresentar um argumento consistente resolvendo a problemática supracitada. A atividade intitulada como "Desafio 24 horas" abarca situações cotidianas que emergem o tempo todo no campo dos negócios e requer tomada de decisões fundamentadas e coerentes em tempo hábil, para que os clientes não desistam de realizar suas compras com uma determinada empresa. Concluímos que nesta lógica, a atividade explorou as atitudes dos pós-graduandos frente a uma problemática que demandou diálogo, colaboração, pesquisa, reflexão e outros valores no âmbito da disciplina de Jogos de Negócios, suscitando o desenvolvimento de uma aprendizagem mais humana e ativa na pós-graduação que instiguem os estudantes a pensar sobre a sua realidade e aproximar o que se aprende na academia com situações que perpassam a vida em sociedade.
\end{abstract}

PALAVRAS-CHAVE: Casos de Ensino; Metodologias Ativas; Práticas de Ensino.

ABSTRACT: The present work describes a teaching case developed for the discipline of Business Games offered by a Lato Sensu graduate in Financial Management at a Higher Education Institution in the city of Viçosa-MG. At the time, the 21 students enrolled in the discipline were divided into four groups and, through WhatsApp, the students interacted with each other in order to solve a teaching case that presented a real problem situation. The interactions were mediated by the technologies and each group received a different customer profile that would need to be studied among the members of each team and, in the end, each group would need to present a consistent argument solving the aforementioned problem. The activity entitled "24-hour challenge" covers everyday situations that emerge all the time in the business field and requires informed and consistent decision making in a timely manner, so that customers do not give up on making purchases with a certain company. In this logic, the activity explored the attitudes of graduate students in the face of a problem that demanded dialogue, collaboration, research, reflection and other values within the scope of the Business Games discipline, prompting the development of a more human and active learning in the post- graduation.

\footnotetext{
${ }^{1}$ Mestre em Administração. Bacharel em Comunicação Social, Professor Formador do Curso Lato Sensu em Mídia e Educação da UNIPAMPA. Professor pesquisador do GEPPFOR UFV. ORCID id: 0000-0002-4890-9307. E-mail: sidney.martins@ufv.br

${ }^{2}$ Mestre em Educação. Licenciado em Química. Professor de Química da SEE-MG. Professor Pesquisador do GEPPFORUFV. ORCID id: 0000-0001-6968-2722. E-mail: mateus.j.santos@ufv.br

${ }^{3}$ Pós-Doutora em Educação. Professora Titular da Universidade Federal de Viçosa. Coordenadora do GEPPFOR-UFV. ORCID id: 0000-0002-7473-9559.E-mail: rmello@ufv.br
} 
KEYWORDS: Teaching Cases; Active Methodologies; Teaching Practices.

\section{INTRODUÇÃO}

O desenvolvimento de uma aula exige do professor um planejamento no qual abarque os tópicos que devem ser desenvolvidos, mas também exige compreensão de metodologias que possam facilitar a assimilação dos conteúdos, sejam eles atitudinais, procedimentais ou conceituais, pelos estudantes (CASTRO; TUCUNDUVA; ARNS, 2008). Quando tais indivíduos estão em nível de pósgraduação, as metodologias exigem do professor competências e habilidades para abordar os conteúdos para além dos conceitos e definições meramente memorísticos, de modo que os estudantes se engajem, participem e colaborem para um desenvolvimento mais rico e dinâmico da aula e que oportunize uma aprendizagem significativa. Essas ferramentas metodológicas podem abarcar as metodologias ativas que já estão em consonância com a Base Nacional Comum Curricular (BNCC) (BRASIL, 2018), documento este que orienta o currículo para a Educação Básica e que também repercute na pós-graduação Lato Sensu que prevê a formação de um profissional atento ao seu universo profissional (BRASIL, 2007). Afinal, práticas de ensino que propiciem uma educação ativa (RANDI; CARVALHO, 2013) devem partir de metodologias que façam com que os estudantes, sejam de qual nível de ensino for, saía da posição de mero reprodutor de informações e comecem a construir um conhecimento permeado pela leitura crítica de mundo e capaz de resolver situações inerentes ao meio em que se encontram inseridos.

Somado a isso, em tempos de pandemia, no qual exigiu das instituições de ensino superior, uma remodelação das práticas pedagógicas e uma inserção em ambientes virtuais devido ao distanciamento social obrigatório em detrimento da disseminação da Covid-19, apesar de configurar-se como um quadro de precarização e fragilidade das redes e sistemas de ensino, os professores tiveram a oportunidade de lançar mão de dezenas de ferramentas metodológicas que auxiliam no desenvolvimento das aulas. Isto vai ao encontro do que Moran (2015) elucida quando nos diz que a escola deve se transformar em um espaço engajador de aprendizados para que os estudantes possam se tornar protagonistas do seu processo educativo. Assim, apesar das muitas adversidades em decorrência da pandemia, as atividades não podem cair em uma pedagogia do mais do mesmo e repetir técnicas e práticas de ensino descontextualizadas com o perfil discente, sobretudo na pós-graduação, que busca preparar o estudante para o universo profissional ou aperfeiçoá-lo, dado que, muitos já se encontram no mercado do trabalho. Na próxima subseção será descrita a importância de se desenvolver práticas de ensino que estimulem o pensamento crítico, dentre elas, a utilização de casos de ensino que privilegiam situações reais que abrangem a vivência profissional dos sujeitos em nível de pós-graduação. 


\section{A IMPORTÂNCIA DO DESENVOLVIMENTO DE CASOS DE ENSINO EM NÍVEL DE PÓS- GRADUAÇÃO}

Um caso de ensino é a descrição de um problema real que requer uma série de habilidades dos discentes com o objetivo de entendê-lo e interpretá-lo utilizando os conhecimentos adquiridos ao longo de uma formação (MAHBOUBIAN, 2010; FARIA; FIGUEIREDO; 2013). Um caso de ensino pode conter elementos fictícios como alguns personagens, mas a situação apresentada deve partir de situações-problemas inseridas no contexto dos estudantes para que eles mobilizem conhecimentos em busca de uma resolução consistente para o que lhe é apresentado. Há diversos meios para se desenvolver um caso de ensino nas aulas, mas é preciso considerar que o mesmo deve partir de uma problemática bem delineada para que os estudantes consigam desenvolver um raciocínio condizente com a situação-problema apresentada (NONO; MIZUKAMI, 2002). Assim, o planejamento dos casos de ensino deve vir antes de sua implementação para que o docente consiga reunir elementos necessários para uma boa escrita de um caso sem comprometer a construção dos conhecimentos pelos seus estudantes.

$\mathrm{Na}$ literatura há diversos trabalhos que abordam os estudos de casos e os casos de ensino. Enquanto o primeiro está atrelado a uma pesquisa propriamente dita, os casos de ensino têm uma função bem delineada e está associado com o desenvolvimento da aprendizagem dos estudantes (ROESCH; 2007; EMMERDOERFER; 2008). Segundo Booth, et al., (2000) um caso para ensino é uma exposição de uma situação que emerge do campo profissional constituindo-se uma fonte rica de dados que representa a complexidade de uma comunidade e/ou simula uma situação real. Quando o planejamento da aula envolve um caso de ensino, o professor deve ter o cuidado de analisar o perfil dos estudantes, a fim de traçar estratégias de como instigá-los a se engajar nas aulas a partir do caso proposto. Durante essa fase de investigação, o professor consegue visualizar as ferramentas que podem proporcionar a aplicação de um caso de ensino bem mais próximo da realidade dos estudantes. Essa aproximação desenvolve o sentimento de pertencimento entre o caso elaborado e os discentes e, portanto, algo de seu conhecimento, podendo oportunizar uma aprendizagem ainda mais ativa e com contribuições efetivas para o futuro profissional do estudante de pós-graduação.

Gil (2004, p. 2) afirma que "o que se espera com o uso dos casos é que o estudante se coloque no lugar da pessoa a quem cabe tomar a decisão ou resolver o problema”. Um caso de ensino pode ser desenvolvido a partir de multinarrativas e facetas e cabe ao docente mapear todos estes olhares e propor mecanismos que auxiliem os estudantes a se posicionarem diante da resolução do caso. Assim, sugere-se que um caso seja realizado em grupos de modo que as ideias se complementem e que, aos pares, os estudantes tenham que chegar a um consenso trabalhando a argumentação e o discurso, 
elementos extremamente importantes para os discentes de uma pós-graduação em Gestão Financeira, por exemplo. Esta alternativa pode favorecer um olhar panorâmico do problema elucidado pelo caso, resultando em uma maior riqueza de detalhes e, com isso, o desenrolar da atividade pode se tornar dinâmico, dialógico e as indagações emergidas desta situação de aprendizagem poderá proporcionar uma ampliação das visões sobre a situação-problema que antes não se tinha.

Partindo destes pressupostos, esse trabalho foi resultado de uma disciplina ministrada para o curso de uma pós-graduação Lato Sensu em Gestão Financeira de uma Instituição de Ensino Superior da cidade de Viçosa-MG, e ao construir o escopo das aulas, havia a necessidade de uma imersão em algo mais próximo aos estudantes e que interagisse com o mercado, a partir de uma situação real e atual. Entretanto, antes de desenvolver o caso propriamente dito, as situações-problemas foram planejadas pelo professor regente após um estudo da realidade em que os estudantes se encontravam inseridos e os casos de ensino só foram implementados após uma conversa com os estudantes e uma escuta empática dos anseios deles com a disciplina. Desse modo, percebeu-se que faltavam situações mais práticas que precisavam ser desenvolvidas, o que desencadeou no desenvolvimento dos casos de ensino aqui descritos. A seguir, serão detalhados os procedimentos utilizados para o desenvolvimento e exposição do caso e os resultados obtidos com esta atividade.

\section{DESENVOLVIMENTO DO CASO DE ENSINO}

Antes de expor o caso de ensino, é importante considerar que no desenrolar da disciplina, esta atividade não foi a primeira a ser realizada junto com os estudantes. Em cada aula, o professor propunha atividades colaborativas e em grupos utilizando WhatsApp como ferramenta pedagógica, nas quais os estudantes precisariam discutir sobre diferentes situações e conceitos abarcados pela disciplina. Esta alternativa preparou os estudantes para o desenvolvimento do caso de ensino, uma vez que, encontravam-se mais desinibidos e já estavam integrados uns com os outros, o que propiciou uma maior interatividade nas aulas. Ellet (2007) aponta que caracterizar um caso de ensino deve lançar mão de alguns aspectos, a saber: provocações significativas, informações necessárias para fundamentar as considerações finais e não indicar ações conclusivas ao longo do caso, mas situações que propiciem o encadeamento das ideias para o desenvolvimento das conclusões.

Cabe reiterar ainda que, a pandemia trouxe a necessidade de interações virtuais. Logo, nada mais coerente de expandir a sala virtual, ou seja, ir além da plataforma disponibilizada aos estudantes e propor outras interações mediadas por ferramentas digitais. Para isso, o uso do WhatsApp se fez necessário, pois essa ferramenta auxilia no apoio mais individualizado e ordenado e o professor tem 
a oportunidade de construir conexões mais sólidas com os discentes a partir de uma interação dialógica (MARTINS; FUJINAMI, 2020) que ocorreu em cada uma das atividades desde o início da disciplina de Jogos de Negócios.

Dado esse interim, os discentes já mais ambientados com o professor e sua dinâmica puderam ser levados a um desafio maior, já que este exigiu desses protagonistas um comportamento para a resolução de problemas, tomadas de decisões, pesquisas investigativas, argumentos consistentes, lista de evidências e estratégias de falácias para a exposição e venda da ideia ao grupo, cujos tópicos faziam parte da ementa da disciplina de Jogos de Negócios. Além disso, as atitudes e valores também fizeram parte dos conteúdos atitudinais presentes no plano de ensino elaborado pelo professor regente e abordados nas aulas. Para a atividade, frente aos perfis dos discentes e a oportunidade de explorar a diversidade de pensamentos, o caso de ensino foi estruturado para um argumento frente à negativa de compra de um produto específico. Em contrapartida, para atender melhor as evidências que os estudantes trouxeram a tona durante as aulas anteriores, ao invés de todos falarem de um produto, deu-se a oportunidade de transformar o caso em um estudo personalizado para cada grupo de estudantes, utilizando o WhatsApp enquanto ferramenta potencializadora das interações em grupo.

Com a turma dividida em quatro grupos, deu-se início ao desenvolvimento do "Desafio 24 horas", nome dado aos casos de ensino que deveriam ser solucionados em apenas 24 horas, buscando avaliar a proatividade dos estudantes em resolver situações-problemas corriqueiras e que demandam pouco tempo para ser solucionadas. Sobre o caso em si, foi desenvolvido pelo professor regente quatro perfis de clientes com características que diferiam um do outro e que precisavam ser incorporadas no discurso da venda. Já com relação ao produto a ser vendido, os estudantes demonstraram interesse em ser um produto tecnológico conhecido por todos, dado o recorrente uso das ferramentas digitais em plena pandemia. Logo, o caso, disponibilizado aos discentes, forneceu as especificações do produto e os estudantes precisariam aprofundar mais nos prós e contras desde objeto para que pudessem desenvolver uma argumentação mais consistente sobre a venda em questão.

Neste trabalho, será discutido o Caso de Ensino $3^{2}$ e seus desdobramentos na formação dos pós-graduandos em Gestão Financeira. A Figura 1 apresenta a proposta do Caso de Ensino lançado aos estudantes do referido grupo e algumas orientações básicas, a priori.

\footnotetext{
${ }^{2} \mathrm{O}$ caso de ensino apresentado é autoral e desenvolvido especificamente para a disciplina Jogos de Negócios do curso
} Lato Sensu em Gestão Financeira. 
Figura 1: Descrição da atividade encaminhada aos estudantes.

Trabalho em grupo

Cada grupo receberá um perfil de cliente, e sobre esse perfil deverão pesquisar seus características para auxiliar na elaboração de um argumento de venda "matador" (eficaz), no qual o cliente consiga repensar sobre sua intenção de compra, já que o potencial cliente disse NÃO para a compra do produto, ao qual você é responsável pela venda.

Atenção:

- Você não pode vender por outro valor a não ser o valor que está anunciado, portanto, não tem combo, mimos extras ou desconto;

- Seu potencial cliente não tem problemas para comprar, ou seja, não é o valor que gerou a negativa da compra; e

- Seu potencial cliente é sedentário e sabe da necessidade de fazer exercícios regularmente (tem a consciência do ser saudável, mas não da pró atividade de fazer algo em prol da saúde própria).

Fonte: Os autores (2021).

Já a Figura 2 expõe algumas dicas sobre a atividade abarcando o Caso de Ensino desenvolvido pelo professor.

Figura 2: Dicas para o desenvolvimento da situação-problema.

Dicas:

- LEIA atentamente o perfil indicado para seu grupo, para que não construa o argumento pautado em achismos;

- PESQUISE mais sobre o perfil do seu potencial cliente;

- DESCUBRA gostos, costumes de seus pares, para que possam ter material na criação do argumento de venda;

- PESQUISE o site indicado (na fonte da descrição do produto), para DESCOBRIR mais sobre o produto e tirar outras informações, inclusive da aba "especificações do produto";

- SAIA de argumentos clichê e instigue o despertar da necessidade (ex.: Steve Jobs com a Apple, como conversado em aula); e

- O exercício ENCERRA (o ENVIO do trabalho) no horário descrito abaixo (1 hora antes do início da aula), portanto, o envio posterior ao horário anunciado, GERARÁ o indeferimento do recebimento do arquivo, inviabilizando a avaliação e por consequência a nota do trabalho realizado.

Fonte: Os autores (2021).

Podemos observar na Figura 2 que, os verbos que iniciam as frases estão escritos com letras maiúsculas e em negrito. Isso faz com que os verbos de ação sejam evidenciados, chamando a atenção dos estudantes para cada ação que deverá ser efetuada em cada um dos procedimentos para o desenvolvimento do caso de ensino. Esta técnica é muito utilizada em atividades educacionais com vistas à potencialização da aprendizagem, uma vez que, ao definir os objetivos de cada ação e expor isso 
em uma situação de aprendizagem, os sujeitos terão a oportunidade de visualizar o que deve ser feito (MAMEDE; ABBAD, 2018). Assim, os verbos, seguem a Taxonomia de Bloom que expõe claramente os objetivos de cada atividade. Segundo Ferraz e Belhot (2010, p. 421), “[...] decidir e definir os objetivos de aprendizagem significa estruturar, de forma consciente, o processo educacional de modo a oportunizar mudanças de pensamentos, ações e condutas".

O caso termina com uma pergunta provocativa e com informações sobre a entrega da atividade:

Cada grupo tem 24 hara enviar a resposta, ou seja, das 17 de hoje às 17 horas de amanhã, essa entrega deve ser feita via WhatsApp em um arquivo PDF.

\section{O produto ao qual você é responsável é o Relógio Inteligente da Arkaika por R\$ 524,39 a uni-}

dade $^{3}$.

A escolha do produto elucidado está pautada em sua ampla divulgação por diferentes empresas e sua praticidade de uso, o que possibilitou a criação de um caso contextual para os estudantes. Após o lançamento da situação-problema, foi fornecido pelo professor o perfil do potencial cliente, sendo que cada cliente já tinha apresentado a negativa para a compra do produto. O perfil do cliente está exposto na Figura 3, a seguir.

Figura 3: Descrição da Atividade encaminhada aos estudantes.

\section{PERFIL DO SEU POTENCIAL CLIENTE}

- Homem

- 27 anos

- Natural de Viçosa / MG

- Mestrando em Entomologia

- Solteiro

- Assexual

- Não tem filhos

- Negro

- Candomblecista

- Morador da Rua dos Estudantes em Viçosa / MG

Fonte: Os autores (2021).

Após o lançamento da situação-problema aludida aos estudantes, eles começaram a debater a partir de interações virtuais propiciadas pelo WhatsApp e sempre supervisionado pelo professor que

${ }^{3}$ Os valores e o nome da empresa fornecedora do relógio inteligente são fictícios. 
ministrou a disciplina. A supervisão do professor tinha o intuito de guiar e fomentar o aprofundamento das pesquisas e encadeamento das ideias para a construção dos argumentos. O papel de mediação do professor suscitou a proatividade dos estudantes a realizarem pesquisas investigativas com o intuito de responder o problema proposto. A seguir, será apresentada e discutida a resolução do caso pelos estudantes do Grupo $3^{4}$.

\title{
RESULTADOS E DISCUSSÃO
}

Após discutirem sobre o caso proposto, durante as 24 horas fornecidas para a execução do exercício, o grupo responsável pelo perfil indicado na Figura 3 entrou em consenso e apresentou o seguinte argumento, dividido em três fragmentos, para o cliente:

\begin{abstract}
"Dadas as considerações supracitadas, salientamos a importância do nosso produto, uma vez que, oferece suporte completo para acompanhamento de exercícios físicos, e se levarmos em conta a dificuldade da sociedade moderna em se exercitar, podemos frisar a relevância do relógio inteligente da Arkaika, uma vez que, de acordo com o perfil do nosso potencial cliente, muitas vezes não frequenta as academias ou outros lugares por uma questão psicológica, talvez por se sentir inferior fisicamente. $O$ relógio inteligente da Arkaika funciona como um personal trainer, $e$ pode ser acionado a qualquer hora do dia ou da noite. Por isso o mercado apresenta essa novidade, o relógio inteligente da Arkaika apelidado por nós de "'o doutor de pulso"'", com ele seus dias serão monitorados por quem entende de saúde". (Fragmento 1 do argumento exposto pelo Grupo 3).
\end{abstract}

Nesta primeira parte do argumento, observa-se uma gama de elementos discursivos que precisam ser analisados com vistas a interpretar a relevância do desenvolvimento de casos de ensino na pós-graduação. Em um primeiro momento, o grupo buscou elementos contextuais para tornar a exposição supracitada rica e incluiu elementos positivos que reforçam a importância de se ter o produto. É importante sublinhar que o cliente já apresentou uma negativa de compra do produto e a riqueza de detalhes expostas no Fragmento 1 mostra articulações entre características implícitas no perfil do potencial cliente com o produto a ser vendido. Um elemento evidente no argumento exposto é a simpatia durante a escrita entrelaçada com elementos ricos que tem um alto poder persuasivo. Com base em Damasceno e Iglesias (2017),

\footnotetext{
${ }^{4}$ A escolha de apenas um dos casos para a discussão neste trabalho está associada à limitação de espaço e as inúmeras situações específicas de cada grupo que merecem ser detalhadas para que possamos compreender o impacto deste tipo de atividade na formação de pós-graduandos. Assim, optou-se por expor apenas um dos casos e uma explicação detalhada da repercussão do mesmo na sala de aula.
} 
As tentativas dos vendedores em aparentarem amigáveis e próximos de seus clientes podem ocorrer por meio de elogios e manifestações de empatia. O consumidor pode simplesmente ter como experiência um ambiente acolhedor e uma afinidade com o comportamento e fala do vendedor, sem sequer suspeitar que isso faça parte de um protocolo de interação planejado. (DAMASCENO; IGLESIAS, 2014, p. 189).

Assim, o desenvolvimento de uma argumentação amigável pode tornar o argumento ainda mais consistente e oferecer ao potencial cliente informações verdadeiras e confiáveis sobre o produto em questão. A seguir, os estudantes continuaram o desenvolvimento do argumento entregue ao professor e fizeram correlações importantes entre o perfil do cliente e as características do produto analisado em questão.

\begin{abstract}
"O perfil do nosso cliente é bem conectado com a natureza, devido a sua área profissional, remete a momentos que exigem concentração, e podemos ressaltar os modos yoga, favorecendo o relaxamento completo e muitas vezes se deliciando ao observar as fotografias retirados pelo relógio inteligente da Arkaika 5 sem depender de outros aparelhos. A vida de solteiro é corridíssima, repleta de compromissos e com o relógio inteligente da Arkaika, ele cuidará da saúde e terá tempo para outros momentos, como se dedicar mais aos estudos. Além disso, ele notifica quando está próximo um evento, auxiliando nos compromissos como as reuniões de candomblé do cliente e eventos que envolvam sua área profissional. O relógio inteligente da Arkaika é muito útil, por exemplo, no monitoramento da atividade física quando se anda de bicicleta e deseja fazer o acompanhamento do treino... e conta com uma bateria que dura 14 dias, longe da realidade de qualquer aparelho do mercado." (Fragmento 2 do argumento exposto pelo Grupo 3).
\end{abstract}

O fragmento 2 exposto pelo grupo analisado apresenta conexões importantes entre o clienteproduto tornando a exposição mais próxima do indivíduo que poderia comprar o objeto em questão. Além de tornar a fala amigável (DAMASCENO; IGLESIAS, 2014), a pessoalidade no discurso torna enriquecedora a exposição e pode promover o desenvolvimento de habilidades para a venda do produto. Nesta lógica, Neves, Sousa e Barbosa (2004) salientam que:

[...] aprender a vender passa a ser uma exigência não só para se alcançar melhores resultados, mas, na medida em que o mercado vai se tornando mais competitivo, a habilidade para vendas passa a ser encarada como uma alternativa capaz de promover maior pessoalidade nas relações com os clientes, assegurando maior proximidade nos relacionamentos comerciais. (NEVES; SOUSA; BARBOSA, 2004, p. 2).

Desta forma, a pessoalidade é uma característica importante no desenvolvimento do discurso no universo dos negócios, pois possibilita uma fuga da linguagem academicista para lidar com pessoas imersas no cotidiano e traz elementos que os sujeitos realmente compreendam sobre o produto 
que deseja adquirir. Por fim, o fragmento 3 do argumento desenvolvimento pelos estudantes conclui a exposição do referido caso de ensino.

\begin{abstract}
"É um produto muito completo com um ótimo custo-benefício. Todos os equipamentos que ele substitui, necessita de espaço para guardar e saem mais caros no mercado. $O$ relógio inteligente da Arkaika faz tudo isso de forma prática e versátil, além de contar com um modelo ultramoderno. Foi desenvolvido pra você cliente que quer viver muito e com qualidade de vida. O relógio inteligente da Arkaika oferece suporte de atividades que exigem vários profissionais, dentre eles podemos citar um personal trainer que cuida do seu corpo, um médico pra cuidar da sua saúde e um administrador para organizar os compromissos e profissionais de yoga. E tudo isso por apenas $R \$ 524,39$. Diante do exposto, podemos perceber que: "Preço é o que você paga, valor é o que você recebe". Este é o momento de mudar de vida, com um produto moderno e repleto de benefícios. Este é o relógio inteligente da Arkaika". (Fragmento 3 apresentado pelo Grupo 3 analisado).
\end{abstract}

Pautado no fragmento apresentado, percebe-se que o grupo se envolveu com a atividade e assumiram a posição de protagonistas do caso de ensino, buscando desenvolvê-lo de maneira clara e consistente. $\mathrm{O}$ fragmento 3 conclui as ideias e fecha a argumentação que está amarrada, com elementos contextuais, linguagem clara e com situações expostas que foram sendo construídos a partir de uma pesquisa investigativa realizada pelos estudantes e evidenciada nas discussões no WhatsApp. A movimentação do grupo em busca da resolução do caso de ensino em questão demonstra a necessidade de desenvolvermos metodologias de ensino mais ativas na pós-graduação que oportunizem com que os profissionais vivenciem efetivamente o mundo do trabalho com situações-problemas contextuais, mais próximas da realidade do mercado, entrelaçando o conhecimento teórico com as nuances inerentes à prática que o exercício profissional exige de cada um. Além disso, os estudantes lançaram mão de conceitos importantes do campo do discurso que auxiliaram na sustentação do argumento aludido, evidenciando um conhecimento amplo da problemática apresentada e o desenvolvimento de um perfil de profissional que respeita seus clientes e busca desenvolver métodos para ampliar os seus negócios.

Cabe salientar ainda que, as ferramentas digitais propostas para a execução do "Desafio 24 horas", foram imprescindíveis na promoção da interatividade e de um espaço mais dialógico, oportunizando o desenvolvimento de uma construção do conhecimento pautado na Educação Relacional (APPLE; WEIS, 1986). A Educação Relacional parte do princípio de que o conhecimento se constrói com o outro, a partir da colaboração e pluralidade de ideias. Desse modo, o diálogo se mostra como elemento indispensável no desenvolvimento de casos de ensino e que, neste caso, foi mediada pelo WhatsApp sob a supervisão do professor (PORTO; OLIVEIRA; CHAGAS, 2017). Reitera-se ainda que, o WhatsApp pode ser uma importante ferramenta aliada ao ensino, sobretudo por permitir que 
os sujeitos se manifestem de forma natural, uma vez que, já estão ambientados com esta plataforma (CARVALHO, 2014).

\section{CONSIDERAÇÕES FINAIS}

O caso de ensino apresentado foi um dos momentos mais dinâmicos desenvolvidos na disciplina de Jogos de Negócios da pós-graduação em Gestão Financeira. A atividade denominada "Desafio 24 horas" abarcou elementos conceituais, pautado na discussão de conceitos e definições abarcadas pelo universo dos negócios, procedimentais, envolvendo os critérios para o desenvolvimento do caso de ensino e atitudinais englobando atitudes e valores imprescindíveis para o desenvolvimento de um profissional qualificado e antenado ao mundo que o cerca. A argumentação, elemento central a ser avaliado ao final do desenvolvimento do caso, também foi concluída com êxito, uma vez que os estudantes desenvolveram suas ideias de forma clara, consistente e coerente amarrando os conceitos chaves da disciplina com a situação-problema aludida.

Esse exercício, apresentado nesse estudo, demandou dos estudantes a interação com outras ferramentas digitais e reflexões metodológicas para a resolução de uma problemática contextual. Os debates no WhatsApp foram acompanhados pelo professor regente e o diálogo foi o precursor da Educação Relacional expondo a necessidade de criarmos situações de aprendizagens coletivas que propiciem uma construção de conhecimentos efetiva e afetiva entre os estudantes e potencializem a interação, não só entre os estudantes, mas entre os estudantes e o professor e entre os estudantes e o mundo que o cerca. Os elementos contextuais disponibilizados no caso foram essenciais para aproximar a situação-problema da realidade dos discentes. Desse modo, planejar atividades com antecedência é primordial para um bom desenvolvimento das práticas pedagógicas no Ensino Superior e possibilita um engajamento dos sujeitos repercutindo em boas ações, tanto no aspecto da aprendizagem quando na formação de um profissional que terá a oportunidade de aperfeiçoar os conhecimentos adquiridos em sua vida acadêmico-pessoal.

No desenvolvimento deste caso, mostra-se que toda a dimensão de conteúdos foi articulada, envolvendo conteúdos conceituais, procedimentais e atitudinais. Ainda, características do discurso como a persuasão e a argumentação crítica foram avaliadas ao longo da proposta, demonstrando a necessidade de explorarmos este campo ainda incipiente nas pesquisas em práticas de ensino na pósgraduação envolvendo o mundo dos negócios. Essa situação vivenciada durante a disciplina de Jogos de Negócios de uma Instituição de Ensino Superior da cidade de Viçosa/MG demonstra que o ensino 
carece de propostas audaciosas que instiguem os estudantes a pensar sobre a sua realidade e aproximar o que se aprende na academia com situações que perpassam a vida em sociedade.

\section{REFERÊNCIAS}

APPLE, Michael; WEIS, Lois. Vendo a educação de forma relacional: classe e cultura na sociologia do conhecimento escolar. Educacão e realidade, v. 11, n. 1, p. 19-33, 1986.

BOOTH, Charles; BOWIE, Stuart; JORDAN, Judith; RIPPING, Ann. The use of the case method in large and diverse undergraduate business programmes: problems and issues. International Journal of Management Education, v. 1, n. 1, p. 62-75, 2000.

BRASIL. Base Nacional Comum Curricular. Brasília: MEC, 2018. Disponível em: http://basenacionalcomum.mec.gov.br/images/BNCC_EI_EF_110518_versaofinal_site.pdf. Acesso em: 30 mar. 2021.

BRASIL. Ministério da Educação. Parecer CNE/CES no 2/2007, aprovado em 31 de janeiro de 2007. Brasília: MEC, 2007. Disponível em: http://portal.mec.gov.br/cne/arquivos/pdf/pces002_07. pdf. Acesso em: 13 dez. 2020.

CARVALHO, Rodrigo Badaró. Alternativas para a proposta de Zygmunt Bauman. Cadernos Zygmunt Bauman, v. 4, n. 7, p. 1-18, 2014.

CASTRO, Patrícia Aparecida Pereira Penkal; TUCUNDUVA, Cristiane Costa; ARNS, Elaine Mandelli. A importância do planejamento das aulas para organização do trabalho do professor em sua prática docente. ATHENA - Revista Científica de Educação, v. 10, n. 10, p. 49-62, 2008.

DAMASCENO, Raissa; IGLESIAS, Fabio. Táticas de persuasão de vendedores em shopping-centers: Um estudo de campo. Psicologia Argumento, v. 32, 2017.

ELLET, William. The case study handbook: How to read, discuss, and write persuasively about cases. Harvard Business Press, 2007.

EMMERDOERFER, Magnus Luiz. Como Escrever Casos para o Ensino de Administração. Revista de Administração Contemporânea, v. 12, n. 4, p. 1187-1188, 2008.

FARIA, Marina; FIGUEIREDO, Klebler Fossati. Casos de ensino no Brasil: análise bibliométrica e orientações para autores. Revista de Administração Contemporânea, v. 17, n. 2, p. 176-197, 2013.

FERRAZ, Ana Paula do Carmo Marcheti; BELHOT, Renato Vairo. Taxonomia de Bloom: revisão teórica e apresentação das adequações do instrumento para definição de objetivos instrucionais. Gestão \& Produção, v. 17, n. 2, p. 421-431, 2010.

GIL, Antônio Carlos. Elaboração de casos para o ensino de Administração. Contextus - Revista Contemporânea de Economia e Gestão, v. 2, n.2, p. 07-16, 2004.

MAHBOUBIAN, Maziar. Educational aspects of business simulation softwares. Procedia-Social and Behavioral Sciences, v. 2, n. 2, p. 5403-5407, 2010. 
MAMEDE, Walner; ABBAD, Gardênia S. Objetivos educacionais de um mestrado profissional em saúde coletiva: avaliação conforme a taxonomia de Bloom. Educação e Pesquisa, v. 44, 2018.

MARTINS, Sidney Pires; FUJINAMI, Fábio Takahashi. Jogos Mortais: O uso das novas tecnologias como uma metodologia de ensino. In: Vander Lúcio Sanches Cândido. (Org.). Educação Significativa. 1 ed. Belo Horizonte: Glauks Edições Acadêmicas, 2020, v. 1, p. 183-194.

MORÁN, José. Mudando a educação com metodologias ativas. Coleção mídias contemporâneas. Convergências midiáticas, educação e cidadania: aproximações jovens, v. 2, n. 1, p. 15-33, 2015.

NEVES, João Adamor Dias; SOUSA, Manoel Messias; BARBOSA, Francisco Sérgio Carneiro. Habilidades profissionais determinantes do sucesso em vendas. Revista Eletrônica de Administração, v. 10, n. 5, 2004.

NONO, Maévi; MIZUKAMI, Maria. Casos de ensino e processos de aprendizagem profissional docente. Revista Brasileira de Estudos Pedagógicos, v. 83, n. 203-04-05, 2002.

PORTO, Cristiane; OLIVEIRA, Kaio Eduardo; CHAGAS, Alexandre. Whatsapp e educação: entre mensagens, imagens e sons. EDUFBA, 2017.

RANDI, Marco Antônio Ferreira; CARVALHO, Hernandes Faustino de. Aprendizagem através de Role-Playing Games: uma abordagem para a educação ativa. Revista Brasileira de Educação Médica, v. 37, n. 1, p. 80-88, 2013.

ROESCH, Sylvia Maria Azevedo. Notas sobre a construção de casos para ensino. Revista de Administração Contemporânea, v. 11, n. 2, p. 213-234, 2007. 